\title{
Pollen and Anther Cultures as Potential Means in Production of Haploid Kenaf (Hibiscus cannabinus L.)
}

\author{
Dwi Susanto, Ahmed Mahmood Ibrahim, Zeti Ermiena Surya Mat Hussin \\ Faculty of Agro Based Industry, Universiti Malaysia Kelantan, Jeli Campus,Jeli 17600, Malaysia \\ E-mail:dwisusanto@umk.edu.my; a_ibrahim1965@yahoo.com;zetiermiena@gmail.com
}

\begin{abstract}
Kenaf (Hibiscus cannabinus L.) is one of the important species of Hibiscus for human needs. It is annual upright plant that produces high biomass, has good adaptability to its environment and inexpensive to be grown. Kenaf has been cultivated in many countries since long time ago mainly for fibers. In Malaysia, however, this plant is considered new and cultivated especially in the eastern parts of Peninsular to replace tobacco plantations that have been no longer supported by the government. This plant has potential to be bred to improve the quality and the adaptability. One of the potential breeding methods to improve the plant is by the production of hybrid varieties. These varieties are superior over the inbred varieties because of the heterosis effect (hybrid vigor) ofF1heterozygous. Hybrid varieties can be produced by reciprocal combinations of crosses among homozygous lines. Homozygous lines conventionally can be achieved by repeated selfing till seven or more generations that need a lot of times. The production of haploid plants in vitro followed by chromosome doubling is a 'short-cut' method to produce homozygous lines in relatively short time compared to conventional methods. The objective of this study is to produce haploid lines through pollen and anther cultures in vitro. The population of haploid plantlets from this research will be induced for diploidization to produce homozygous-heterogeneous population as a basis for the production of hybrid varieties. Preliminary result showed that callus can easily be induced from the anthers compared those from the pollen grains.
\end{abstract}

Keywords - Anther; Haploid; Hybrid Variety; Kenaf; Pollen.

\section{INTRODUCTION}

As a member of genus Hibiscus, kenaf (Hibiscus cannabinus L.) has an important role for human needs. It is usually cultivated for fibers, but when harvested at immature stage, the young kenaf plants can be used for cattle feed [1].In Nigeria, this plant is also used as vegetable [2]. The plant belongs to the class Magnoliopsida (Dicotyledons), subclass Dilleniidae, order Malvales, and family Malvaceae [3]. It is annual upright plant that produces high biomass, has good adaptability to its environment and inexpensive to be grown[4].

It is widely cultivated in many countries. Five major producing countries (Bangladesh, China, India, Nepal, and Thailand) produce kenaf and other fibber plant for about 95\% [5].In Malaysia, this plant has a potential to be improved and cultivated to replace tobacco plantations that are not supported by government anymore. The production of hybrid varieties is a potential method to improve this plant. These varieties are superior over the inbred varieties because of the heterosis effect of F1 heterozygous.

References [6] and [7] have evaluated the heterosis effect and combining ability of this plant. To produce hybrid varieties, reciprocal combinations of crosses among homozygous lines must be made. Homozygous lines conventionally can be achieved by repeated selfing till seven or more generations that need a lot of times. With successive generations, the heterozygosity decreases by $1 / 2$ with each generation to achieve a relatively homozygous condition.

Haploid plants are the plants which posses a gametophytic number of chromosomes in their sporophytes. The interest in haploids is largerly from their considerable potential in plant breeding, especially for the production of homozygous plants and in their studies on detection of mutants [8]. Reference [9] has successfully produced haploid plantlet through somatic embryogenesis from the pollen grains cultured on Murashige and Skoog (MS) medium supplemented with 1-10 mg/l 2,4dichlorophenoxyacetic.

Haploid plants have been effectively produced in many Right now the Malaysian government has been trying to promote kenaf as the nation's third commodity crop - after palm oil and rubber - [14]. Therefore any efforts to improve the genotypes of this plant for further research especially in producing hybrid varieties should be considered and explored. 
An ongoing project founded by FRGS to generate haploid kenaf plants has been sanctioned at the Faculty of Agro Based Industry, Universiti Malaysia Kelantan. The research work has started in the month March 2012. The objectives of this study are (i) to optimize media for micro propagation of kenaf, and (ii) to produce haploid lines through pollen and anther cultures in vitro..

\section{MATERIALS AND METHODS}

\section{A. Plant Materials}

The seeds of kenaf variety KB 6 have been collected from Mardi, Telung Kelantan and grown in Agro Park Universiti Malaysia Kelantan, Jeli Kampus, Kelantan.

\section{B. Micropropagation of Kenaf}

In vitro propagation of kenaf has been carried out as described in [15] using MS media with some modification of plant hormone, vitamin and other organic compounds. The young leaves and petioles have been collected from the mother plant. After that, leaves and petiole were gently washed in warm water and mild detergent and rinse under tap water for 10 minute. Leaves and petioles were dipped in the $70 \%$ ethanol using forceps.

The explants were put in the solution of $10 \%$ chlorine bleach for $5 \mathrm{~min}$, then were brushed with water colour brush for $5 \mathrm{~min}$, rinsed each leaf with 3 times in the sterile distilled water for 5 minute each time. Explants were placed in sterile petri dish. Leaves were cut into section $1 \mathrm{~cm}$ square, and the petioles were cut into $1 \mathrm{~cm}$ length. The explants were put into the MS medium supplemented with different combination of plant growth regulators. Each jar was sealed and placed in an incubator for 4 weeks.

\section{Production of Haploid}

The protocol as describe in [17] with some modification will be applied in this research to produce haploid plants. Flower buds from different ages will be collected from the mother plants, and then chilled for 3-12 days $\left(7\right.$ to $\left.8^{\circ} \mathrm{C}\right)$ in a refrigerator unit. The flower buds will be immersed in $70 \%$ ethanol for $10 \mathrm{~s}$, followed immediately by $10 \mathrm{~min}$ in $2 \%$ $(\mathrm{v} / \mathrm{v})$ hypochlorite, and then washed by immersion for $5 \mathrm{~min}$ in three changes of sterile distilled water $(\mathrm{dH} 2 \mathrm{O})$ under a laminar hood. The buds are teased carefully to open and then the anthers are taken out gently. One anther from each group of flowers is taken and squashed in aceto carmine stain to determine the stage of pollen development. For each culture, anthers from flower buds are placed in $5 \mathrm{ml}$ of liquid medium in a petri dish. After regular intervals of 6 , 10 and 14 days of culture, the anthers are removed from the culture and discarded. That ensures the dehiscence of all anthers and release of pollen into the culture medium.

The dishes are then sealed with para film and incubated at $28^{\circ} \mathrm{C}$ in darkness for the first 14 days of culture. After 14 days, the cultures are transferred to a growth chamber illuminated with florescent tube light (light intensity: 500 lux, day length: 12-h, room temperature: $25 \pm 2{ }^{\circ} \mathrm{C}$. The medium for haploid production consists of $4.4 \mathrm{~g} \mathrm{MS}$ prepared powder, $30 \mathrm{~g}$ sucrose and $8 \mathrm{~g}$ agar powder. Both MS prepared powder and sugar are diluted in about $100 \mathrm{ml}$ of $\mathrm{dH} 2 \mathrm{O}$ each separately. After that the diluted MS powder and diluted sucrose are put in the measuring cylinder containing $500 \mathrm{ml}$ of $\mathrm{dH} 2 \mathrm{O}$. The volume is adjusted to $1000 \mathrm{ml}$, and then added with $1 \mathrm{mg} / \mathrm{L}$ stock of Kinetin and $0.5 \mathrm{mg} / \mathrm{L}$ of IBA. The $\mathrm{pH}$ solution is adjusted to 5.7 to 5.8 , and then $8 \mathrm{~g}$ of tissue culture agar is added to the solution.

The solution is divided into 2 bottles of $500 \mathrm{ml}$ each. Caps are closed untied and covered with aluminium foil, and then autoclaved at $121{ }^{\circ} \mathrm{C}$ for $20 \mathrm{~min}$. The medium is distributed to the jars and test tube (in laminar flow). The diagrammatic figure for the production of haploid plants can be seen in Fig. 1 below as illustrated in [17].



Fig. 1 Diagrammatic figure of production haploid plants through pollen and anther culture

\section{RESULTS AND CONCLUSION}

From the preliminary data collected it is possible to culture kenaf in vitro using explants from leaves (Fig. 2), while those from petioles tended to be more difficult to form callus. The formation of callus and shoot from these cultures then can be induced to form the roots with suitable hormones.

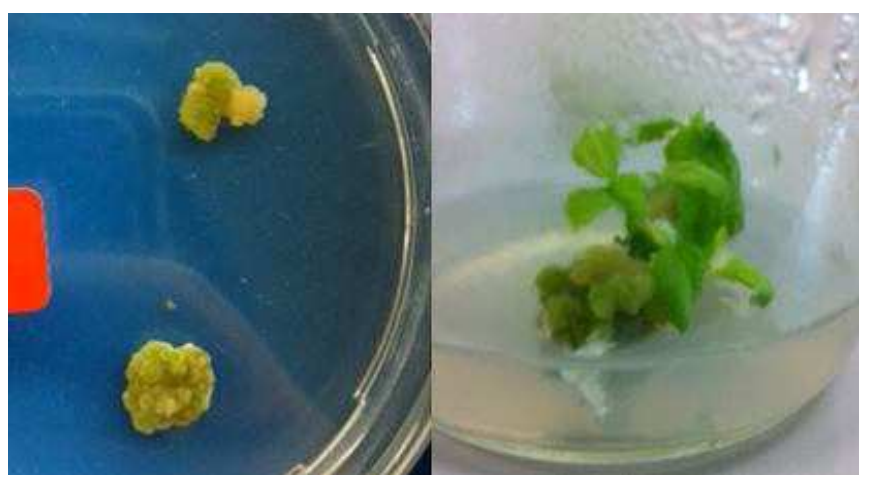

Fig. 2 Callus and shoot regeneration from (diploid) leaf explants 
For haploid production, we could get callus from the anther cultures (Fig. 3), while from the pollen grains works are still in progress.

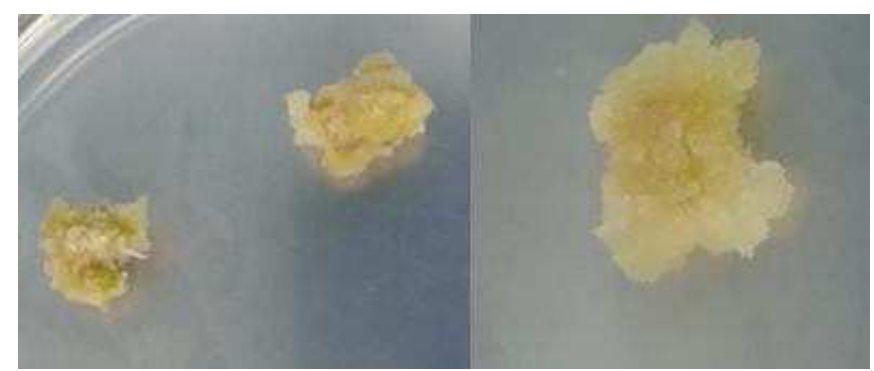

Fig. 3 The development of haploid callus from anther culture

Haploid plants are commonly sterile. Once they are produced, chromosome doubling could make them fertile. The collection of heterogeneous haploid and heterogeneous homozygous dihaploid plants can be used as valuable basic material for the crop improvement in kenaf especially to produce hybrid varieties.

\section{ACKNOWLEDGMENT}

We are highly grateful to the Ministry of Higher Education Malaysia for FRGS grant, to Mardi Telung for providing the seeds of kenaf and also to Universiti Malaysia Kelantan for providing the infrastructure for the research.

\section{REFERENCES}

[1] Webber, C.L. III and V.K. Bledsoe. Kenaf Yield Components and Plant Composition. Reprinted from: Trends in new crops and new uses. 2002. J. Janick and A. Whipkey (eds.). ASHS Press, Alexandria, VA. (2002)

[2] Kubmarawa, D., I. F. H. Andenyang and A. M. Magomya. Proximate composition and amino acid profile of two nonconventional leafy vegetables (Hibiscus cannabinus and Haematostaphis barteri).African Journal of Food Science Vol. 3(9), (2009), 233-236, September, 2009

[3] USDA. Hibiscus cann abinus L. brown Indian hemp. Natural Resources Conservation Service. http://plants.usda.gov/java/profile?symbol=HICA5. Accessed on 14 June, 2010

[4] Jianguang, S.U. and D.A.I. Zhigang. The protection, study and utilization of kenaf (Hibiscus cannabinus) germ plasm in China. 2007 International Symposium on Kenaf and Allies Fibres June 1921,2007, Xiamen, China

[5] Aimin, L. Kenaf (Hibiscus cannabinus L.) Research and development in the international jute organization (IJO) In:Proceedings of the Third Ann. Conf. Amer. Kenaf Soc.,(2000),Corpus Christi, Texas, USA

[6] Patil, R.C. and M.V. Thombre. Heterosis and combining abilitystudies in Hibiscus cannabinus(L.). Journal of Maharashtra Agricultural Universities,5 (52), (1980), 123-126.

[7] Pace, S., I. Piscioneri and I. Settanni. Heterosis and combining abilityin a half diallel cross of kenaf (Hibiscus cannabinus L.) Abstract. Industrial Crops and Products, 7 (2-3), (1998), 317-327. 